\title{
Clinical Implications of Risk and Prognostic Factors in Patients with Breast Carcinomas
}

\author{
Jaafar Makki \\ Department of Pathology, Queen Elizabeth Hospital, Kota Kinabalu, Sabah, Malaysia
}

Corresponding Author: Jaafar Makki, MBchB, DCP, PhD, Senior Pathologist, Department of Pathology, Queen Elizabeth Hospital, Kota Kinabalu, Sabah, Malaysia. Tel: +60136078435; Fax: 006-88-517542; E-mail: jaafer58@hotmail.com

\begin{abstract}
Cancer of the breast is one of the most common human neoplasm, many environmental, personal and genetic factors have been implicated as a risk factors to develop breast cancer. Tumor size, histological subtype, grading, lympho-vascular permeation, and lymph node involvement are the cardinal independent factors influence prognosis and response to different therapeutic modalities. Among other prognostic factors, ER/PR status, Her2 oncogen, DCIS/invasive component ratio, and local tumor spread are highly impact prognosis and systemic anticancer therapy. Recently some molecular markers came out to the scene, as p53 mutations and Bcl-2 amplification, which can be detected by gene-expression profiling, are associated with higher probability of tumor recurrence and low overall survival. In fact, different molecular and histological subgroups show variable prognosis and different response to chemotherapy and other treatment regimes. Finally, we are looking for further studies to improve current prognostic markers that will reflect on better treatment tools.
\end{abstract}

Received Date: September 21, 2015 Accepted Date: November 2, 2015 Published Date: November 6, 2015

Citation: Makki, J. Clinical Implications of risk and prognostic factors in patients with breast carcinomas. (2015) Intl J Cancer Oncol 2(3): 1-9.

DOI: $10.15436 / 2377-0902.15 .022$

Keywords: Breast cancer; Breast cancer risk factors; Breast cancer prognostic factors; Breast cancer grading system.

\section{Introduction}

\section{Breast carcinoma}

Cancer of the breast is one of the most common human neoplasm, accounting for approximately one quarter of all cancers in females worldwide and $27 \%$ in advanced country with the western lifestyle ${ }^{[1]}$. Breast cancer can also occur in men, it is more than 100 times more common in women than in men, which usually have bad prognosis due to delays in diagnosis ${ }^{[2]}$. Breast cancers can be derived from any cell in the mammary gland, they exhibit a wide scope of morphological features and unique histopathological subtypes have specific clinical course and outcome. Now a day with the wide use of mammography as screening tool, more cases of pre-invasive breast lesions are detected. The WHO Working Group agreed that more clinical follow-up and genetic data are needed for a better understanding of the natural history of these lessions ${ }^{[3]}$.

Most of breast malignancies are adenocarcinomas, it constitute more than $95 \%$ of breast cancers ${ }^{[4]}$. Invasive ductal carcinoma (IDC) is the most common form of invasive breast cancer. It accounts for $55 \%$ of breast cancer incidence upon diagnosis ${ }^{[5]}$. Breast carcinomas arise from cells in the terminal duct lobular unit (TDLU). The typing of invasive breast cancer and its histological variants is well established. In general, breast carcinoma divided into in situ carcinomas, ductal carcinoma insitu (DCIS), and invasive ductal carcinomas. DCIS is non invasive potentially malignant intraductal proliferation of epithelial cells that is confined to ducts and lobules. Invasive or infiltrative carcinoma refers to malignant abnormal proliferation of neoplastic cells in breast tissue, which has penetrated through the duct wall into stroma. Invasive carcinoma and carcinoma insitu were classified as ductal and lobular based on the site from which the tumor was raised, Cancers originating from ducts are known as ductal carcinomas, while those 
originating from lobules are known as lobular carcinomas. However, it is now thought that this sort of tumor growth variation is not related to the site or cell of origin, but could be differences in tumor cell biology, as whether the tumor cells express E-cadherin or not ${ }^{[4]}$ (Table 1).

Table 1: Primary Tumor $(\mathrm{T})$

\begin{tabular}{|l|l|}
\hline symbol & Tumor description \\
\hline TX & Primary tumor cannot be assessed \\
\hline T0 & No evidence of primary tumor \\
\hline Tis & Carcinoma in situ \\
\hline Tis (DCIS) & Ductal carcinoma in situ \\
\hline TIS (LCIS) & Lobular carcinoma in situ \\
\hline TIS & $\begin{array}{l}\text { Paget's disease of the nipple is NOT associated with } \\
\text { invasive carcinoma and/or carcinoma in situ (DCIS } \\
\text { and/or LCIS) in the underlying breast parenchyma. }\end{array}$ \\
\hline paget's & Tumor $\leq 20 \mathrm{~mm}$ in greatest dimension \\
\hline T1 & Tumor $\leq 1 \mathrm{~mm}$ in greatest dimension \\
\hline T1mi & Tumor $>1 \mathrm{~mm}$ but $\leq 5 \mathrm{~mm}$ in greatest dimension \\
\hline T1a & Tumor $>5 \mathrm{~mm}$ but $\leq 10$ mm in greatest dimension \\
\hline T1b & Tumor $>10 \mathrm{~mm}$ but $\leq 20$ mm in greatest dimension \\
\hline T1c & Tumor $>20 \mathrm{~mm}$ but $\leq 50$ mm in greatest dimension \\
\hline T2 & $\begin{array}{l}\text { Tumor }>50 \mathrm{~mm} \text { in greatest dimension } \\
\text { wall and } / \text { or to the skin (ulceration or skin nodules) }\end{array}$ \\
\hline T3 & $\begin{array}{l}\text { Extension to the chest wall not including only pectora- } \\
\text { lis muscle adherence/invasion. }\end{array}$ \\
\hline T4 & $\begin{array}{l}\text { Ulceration and/or ipsilateral satellite nodules and/or } \\
\text { edema (including peau d'orange) of the skin, which do } \\
\text { not meet the criteria for inflammatory carcinoma. }\end{array}$ \\
\hline T4a & Both T4a and T4b \\
\hline T4b & Inflammatory carcinoma \\
\hline T4d & tirect extension to the chest \\
\hline
\end{tabular}

Age

Breast cancer can develop at any age from childhood to old age ${ }^{[6]}$. The incidence of breast cancer increases with age, doubling about every 10 years until the menopause, when the rate of increase slows down, but the chance of getting breast cancer goes up as a woman gets older ${ }^{[7]}$.

\section{Incidence and Epidemiology}

Invasive breast cancer is the most common carcinoma in women. It accounts for $23 \%$ of all female cancers, $27 \%$ in affluent countries ${ }^{[1]}$. In 2008, breast cancer caused 458,503 deaths worldwide $(13.7 \% \text { of cancer deaths in women })^{[2]}$. The affluent developed countries are high rick areas where $6 \%$ of women developed invasive breast cancer before age of 75, while developing countries of Africa and Eastern Asia shows one third of that percent. Elsewhere in the globe, the rate is intermediate ${ }^{[3]}$. In the United States, aapproximately 232,340 new cases of invasive breast cancer and 39,620 breast cancer deaths are expected to occur in 2013. One in eight women in the United States will develop breast cancer in her lifetime ${ }^{[8]}$.

Recently, the detection of early carcinoma insitu and small localized invasive lesion, has been increased dramatically by widespread use of mammography, unfortunately, this achievement did not translate into improved survival rate ${ }^{[6]}$.

Breast cancer incidence increased considerably during and after 1990 all over the world, indicating important differences in the distribution of the underlying causes. Environmental factors including geographical variations, diet, time trends and social relation seems to play important role in the aetiology of breast cancer supported by studies of migrant populations from low to high risk areas, which shows those migrants approach the risk of that particular area in next generations ${ }^{[3]}$. Recently, in most of the developed countries, the mortality rate of breast cancer start to decrease may be because of the combined action of earlier diagnosis and improved therapy ${ }^{[6]}$.

\section{Aetiology and Risk Factors}

Breast cancer result from an interaction between an environmental (external) factors and a genetically susceptible host, the aetiology is multifactorial, including many risk factors. Epidemiological studies has shown that breast cancer is more prevalence in developed affluent countries with their characteristic lifestyle of high protein and high-caloric diet rich in animal fat along with low physical activity.

Breast cancer more than other human neoplasm shows familial tendency ${ }^{[3]}$, some genetic susceptibility may play a minor role in most of the cases ${ }^{[9]}$. Overall, however, genetics is believed to be the primary cause of $5-10 \%$ of all cases ${ }^{[10]}$.

Several risk factors for the development of breast carcinoma have been established, whereas many others remain questionable ${ }^{[11]}$. It has been proposed that strong and/or prolonged oestrogen stimulation operating on a genetically susceptible background is the most influencing risk factor for the development of breast cancers ${ }^{[12]}$. The following pages describe the well known risk factors.

Factors Related to Reproductive Lifestyle: Breast cancer is more frequent in women who start menstruating early in life or who have a late menopause. Nulliparity and late age at first birth both increase the incidence of breast cancer ${ }^{[13]}$. Infertility and lack of breast feeding appears to be risk factors. Women who give birth and breast-feed after age of 30 have doubles the risk compared to having first live birth at age less than 25. Never having children triples the risk $^{[4]}$. A reduction in the risk of breast carcinoma among premenopausal women who have lactated has been documented, but no such effect was detected among postmenopausal women ${ }^{[14]}$.

Exogenous Hormones: There are three types of hormonal compounds used as hormonal therapy have been claimed as a risk of developing breast cancer, oral contraceptives, unopposed estrogen therapy and menopausal replacement therapy. There is a little, if any, increase in risk of having breast cancer associated with the use of contraceptive, even after 10 years using these preparations ${ }^{[1]}$. The duration of use, age at first use, dose and type of hormone within the contraceptives appear to have no significant effect on breast cancer risk ${ }^{[13]}$.

The relationship between postmenopausal replacement therapy and development of breast cancers has been intensively studied; these studies have observed significant association between long term use of hormonal replacement therapy and increased risk of developing breast cancer ${ }^{[4]}$.

The use of unopposed estrogen therapy with the longest 
duration has been investigated in many epidemiological studies; significant increased risk of developing breast cancer has been observed $^{[1]}$. In December 2002, the hormone estrogen was declared a known human carcinogen by the National Toxicology Program $^{[4]}$.

Endogenous Hormones: Increased blood levels of endogenous androgen, estrogens and progesterone are associated with an increased risk of breast cancer, in which its incidence rate rise more steeply with age, till menopause where it start to decline when the ovarian sex hormone production diminished ${ }^{[1]}$. However, not only sex hormones, but also increased circulating insulin levels is significantly associated with the risk of breast cancer ${ }^{[15]}$.

The risk of estrogens on breast cancer depends directly on breast tissue exposure. It has been shown in vitro studies that there is an increased of breast cell proliferation and inhibition of apoptosis when the estrogen is administered. Risk of breast cancer is more increased when the circulating and tissue levels of estrogens and progesterone is elevated, which can be observed during the luteal phase of menstrual cycle rather than the follicular phase when there is marked physiological proliferation of breast epithelial cells ${ }^{[3]}$.

Nutrition: There is a close correlation between the incidences of breast cancer and dietary intake in populations. Generally speaking, high caloric intake, saturated animal fat and red meat consumption are possibly associated with an increased risk of developing breast cancer, especially for postmenopausal women. While poultry consumption have no risk ${ }^{[1]}$. Health dietary pattern of high fruit and vegetables intake may be associated with a slightly reduced risk of breast cancer ${ }^{[3]}$. However, recent studies done by Ewertz M, and fackenthal JD suggest that there were an exaggeration stated to the risk of animal source diets and to the preventive effect of vegetables and fruit rich diets ${ }^{[16,17]}$.

Alcohol Intake: According to the International Agency for Research on Cancer, there is sufficient scientific evidence to classify alcoholic beverages as a Group 1 carcinogen that causes breast cancer in women ${ }^{[18]}$. Some studies have shown a link between alcohol consumption and incidence of breast cancer ${ }^{[13]}$. The more alcohol a woman drinks, the more likely she is to get breast cancer. The relationship is linear and dose-dependent. Even low levels of alcohol consumption carry some risk ${ }^{[18]}$.

Body Weight: High body mass as a sequel of high caloric diets intake, or intake not counterbalanced by caloric consumption, along with higher body weight will increases risk to develop breast cancer among postmenopausal women, moreover, this relationship is independent of reproductive risk factors and status of physical activity and has stepwise increase with age ${ }^{[3]}$. Furthermore, studies have shown that obese women are more likely to have large tumours, greater lymph node involvement, and poorer breast cancer prognosis with $30 \%$ higher risk of mortality ${ }^{[19]}$.

Physical Activity: Lack of exercise and low physical activity has been linked to breast cancer ${ }^{[20]}$. Gaining of weight after menopause can increase the risk of having breast cancer. The decrease in risk among the most physically active women was about $20-40 \%$. Activity that is sustained throughout lifetime, possibly of benefit to reduce the risk. It appears that physical activity is independent of race or ethnicity; it has been observed that the best way to avoid breast cancer is to maintain high level of physical activity throughout the lifetime ${ }^{[1]}$.

Family History And Genetic Predisposition: Breast cancer risk is higher among women whose close blood relatives have this disease. Still, most women who get breast cancer do not have a family history of this disease. The risk of developing breast cancer is more if the relative got the disease at an early age of $\operatorname{life}^{[3]}$. Patients with bilateral breast cancer, or get the disease at an early age and those who develop metachronous breast cancer and another epithelial cancer, are most likely to have abnormal gens that has predisposed them to developing breast cancer ${ }^{[13]}$. Breast cancers shows familial tendency more than other human neoplasm, approximately $5-10 \%$ of all breast cancers are famil$\mathrm{ial}^{[21]}$. Two breast cancer genes, BRCA1 and BRCA2, have been identified and account for a substantial proportion of very high risk to developing breast cancer ${ }^{[1]}$, those patient are laible to develope other cancers in particular ovarian cancers ${ }^{[21]}$.

In addition to BRCA1 and BRCA2, several other genes are linked to a variable risk of development of breast cancer. Familial breast cancer can also presented in combination with other cancers as multiple cancer syndromes ${ }^{[6]}$.

Radiation Exposure: Exposure to ionizing radiation increases risk of developing breast cancer later in life, particularly when exposure is during rapid breast formation. Women who have received high-dose ionizing radiation for the treatment of other cancers to the chest, have a relative risk of breast cancer between 2.1 to 4.0 , the risk increases with increased dose ${ }^{[23]}$. Meanwhile, contra lateral breast cancer has been shown to develop after exposures of high dose radiation used during radiotherapy for breast cancer, moreover, patients with Hodgkin's disease receiving radiotherapy at high doses are at high risk to develop breast cancer $^{[24]}$.

Benign Proliferative Lesion: Women with severe atypical epithelial hyperplasia have a four to five times higher risk of developing breast cancer than that of the control population, if those women have a family history of breast cancer (first degree relative), the risk will increase nine times, while patient with other breast benign proliferative lesion have slightly higher risk of developing breast cancer than women who do not have any proliferative changes in their breast ${ }^{[13]}$. The fibrocystic changes per se is not independent risk factor to develop breast cancer, but rather the presence of some potentially premalignant lesion such as flat epithelial atypia and atypical ductal hyperplasia determine the risk to have subsequent breast cancer ${ }^{[6]}$. (Figure 1) shows the possible interaction between risk factors 19 . 


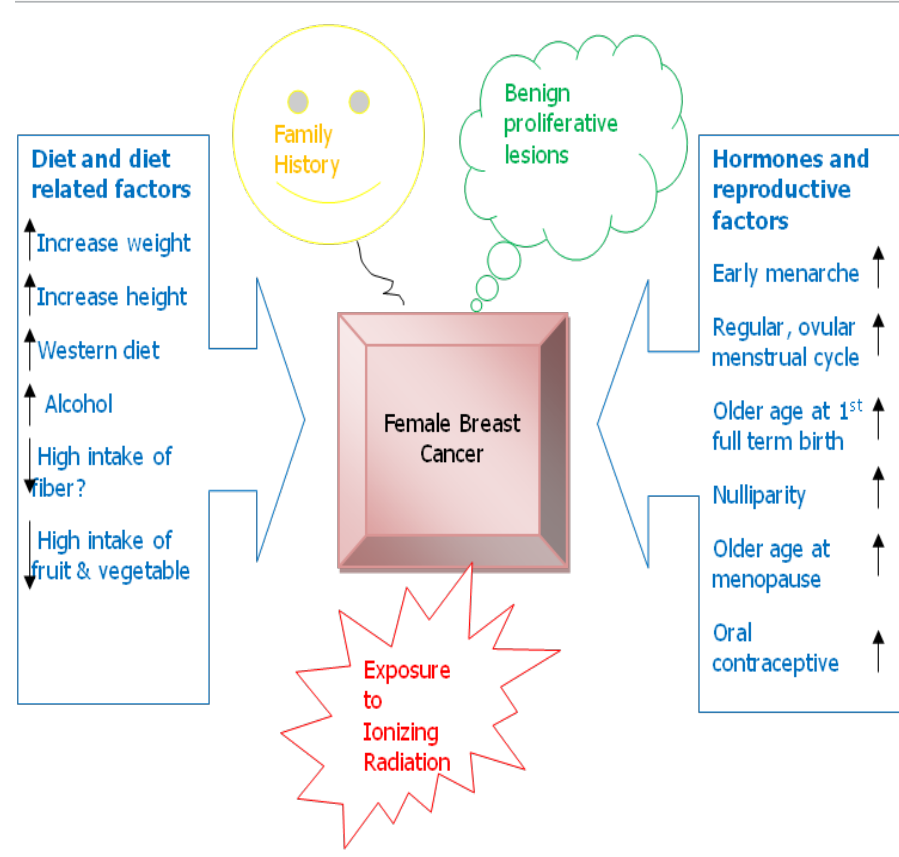

Figure 1: Interaction of risk factors, modified (3).

\section{Location}

The upper outer quadrant of the breast is the most frequent site for breast cancer to arise. Philippa ${ }^{[25]}$ study results are inconsistent with that current view that the high level of upper outer quadrant breast cancer is due solely to a greater amount of target epithelial tissue in that region. The incidence of breast cancer is slightly more in left breast rather than the right side as documented by several studies and the excess for the left side can be up to $13 \%{ }^{[6]}$.

\section{Histological Grading Of Invasive Carcinoma}

Within the last decade, histological grading has become widely accepted as a powerful indicator of prognosis in breast cancer. The majority of tumour grading systems currently employed for breast cancer combine nuclear grade, tubule formation and mitotic rate. The two most widely used systems over the years for the microscopic grading of IDC have been those of original Bloom - Richardson system and Black method, the first based mainly on architectural features (extent of tubular formation) and the second on the degree of nuclear atypia. Since both architecture and cytological features have been found to correlate with prognosis, the sensible proposal has been made to use them in conjunction.

Elston, et $\mathrm{al}^{[26]}$ modification of those two systems is preferred and becoming more popular, which is usually referred to as the Nottingham modification of the Bloom-Richardson system and which also incorporates the evaluation of mitotic activity. Then, the grade is obtained by adding up the scores for tubule formation, nuclear pleomorphism, and mitotic count, each element is given a score of 1 to 3 ( 1 being the best and 3 the worst) and the score of all three components are added together to give the "grade". The lowest possible score $(1+1+1=3)$ is given to well differentiated tumours that all form tubules and have a low mitotic rate $(<10 / 10 \mathrm{HPF})$. The highest possible score is $9(3+3+3=9)$ is given to poorly differentiated tumours ${ }^{[27]}$ (Figure 2).

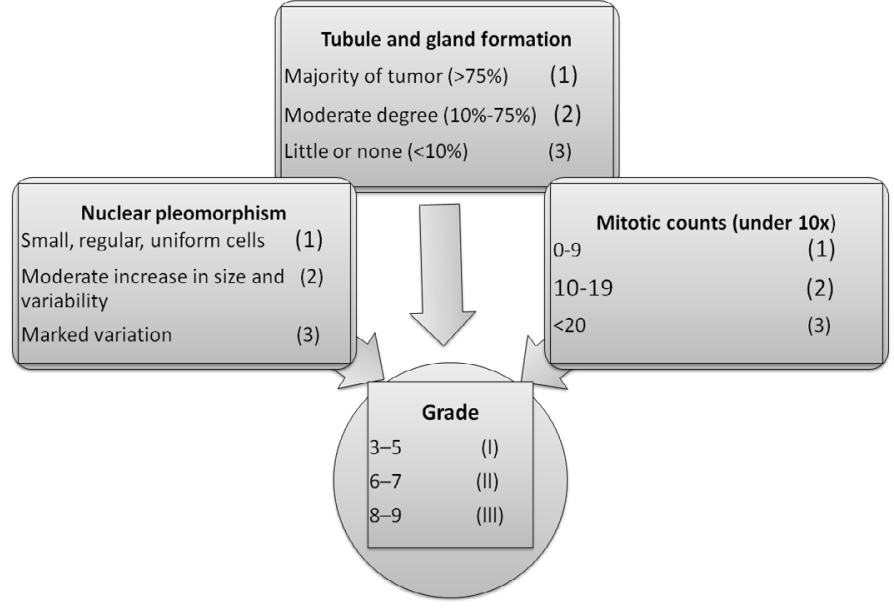

Figure 2: Nottingham/ Bloom-Richardson Grading system

It has been deduced to the point that incorporation of this information into the routine pathology report has become a requirement. The system was largely conceived for invasive ductal carcinoma NOS, but it can also be applied to the special types of ductal carcinoma and to lobular carcinoma ${ }^{[6]}$.

\section{Spread and Metastases}

Breast carcinoma spreads by direct invasion, by the lymphatic route, and by the blood vessel route. Some of these metastases are already present at the time of diagnosis, and others become manifest clinically months, years, or decades after the initial therapy.

Direct Invasion: The malignant cells can invade locally to the stroma, nipple, skin, and chest wall structures like striated muscle and fascia. The invasion of the breast stroma can be by direct extension, via intramammary lymph vessels, and possibly via the tissue spaces (pseudoangiomatous stromal hyperplasia) ${ }^{[28]}$. The degree of local invasion is generally greater in invasive lobular carcinoma and its variants, probably due to the non cohesive nature of tumour cells and the lack of E-cadherin in the tumour cells ${ }^{[29]}$. Nipple invasion has been found in $23-31 \%$ of all clinically detectable invasive carcinomas ${ }^{[30]}$. Tumour recurrence following local excision often develops in the same breast segment. Local recurrence following mastectomy presented as superficial nodules in or near the surgical scar. Women who develop local recurrences are more susceptible to have distant metastase ${ }^{[6]}$.

Lymph Node Metastasis: There are two groups of lymph nodes are commonly infiltrated by the breast carcinoma, the internal mammary and the ipsilateral axillary lymph node, with the supra-clavicular area representing extension of the later. It should be remembered that it is not too unusual to also find lymph nodes within the substance of the mammary gland intramammary lymph nodes' ${ }^{[31]}$. Axillary node metastases are present in $40-50 \%$ of clinically detectable cases. Supraclavicular lymph node involvement is detected in $20 \%$ of patients with axillary lymph node involvement but is almost zero in cases with negative axillary lymph node involvement ${ }^{[32]}$. The second group of lymph node is the internal mammary chain, about $22 \%$ of clinically detectable mammary carcinoma presents with involvement of this Lymph Node Group ${ }^{[6]}$ (Table 2, Table 3). 
Table 2: Regional Lymph Nodes (N), Clinical evaluation

\begin{tabular}{|c|c|}
\hline Symbol & Clinical evaluation of lymph node status \\
\hline NX & $\begin{array}{l}\text { Regional lymph nodes cannot be assessed (e.g., previ- } \\
\text { ously removed). }\end{array}$ \\
\hline No & No regional lymph node metastases. \\
\hline N1 & $\begin{array}{l}\text { Metastases to movable ipsilateral level I,II axillary lymph } \\
\text { node (s). }\end{array}$ \\
\hline \multirow{3}{*}{$\mathrm{N} 2$} & $\begin{array}{l}\text { Metastases in ipsilateral level I, II axillary lymph nodes } \\
\text { that are clinically fixed or matted. }\end{array}$ \\
\hline & OR \\
\hline & $\begin{array}{l}\text { Metastases in clinically detected ipsilateral internal mam- } \\
\text { mary nodes in the absence of clinically evident axillary } \\
\text { lymph node metastases. }\end{array}$ \\
\hline $\mathrm{N} 2 \mathrm{a}$ & $\begin{array}{l}\text { Metastases in ipsilateral level I, II axillary lymph nodes } \\
\text { fixed to one another (matted) or to other structures. }\end{array}$ \\
\hline $\mathrm{N} 2 \mathrm{~b}$ & $\begin{array}{l}\text { Metastases only in clinically detected ipsilateral internal } \\
\text { mammary nodes and in the absence of clinically evident } \\
\text { level I, II axillary lymph node metastases. }\end{array}$ \\
\hline \multirow{5}{*}{ N3 } & $\begin{array}{l}\text { Metastases in ipsilateral infraclavicular (level III axillary) } \\
\text { lymph node (s) with or without level I, II axillary lymph } \\
\text { node involvement. }\end{array}$ \\
\hline & OR \\
\hline & $\begin{array}{l}\text { Metastases in clinically detected ipsilateral internal mam- } \\
\text { mary lymph node (s) with clinically evident level I, II ax- } \\
\text { illary lymph node metastases. }\end{array}$ \\
\hline & OR \\
\hline & $\begin{array}{l}\text { Metastases in ipsilateral supraclavicular lymph node(s) } \\
\text { with or without axillary or internal mammary lymph node } \\
\text { involvement. }\end{array}$ \\
\hline N3a & Metastases in ipsilateral infraclavicular lymph node (s). \\
\hline $\mathrm{N} 3 \mathrm{~b}$ & $\begin{array}{l}\text { Metastases in ipsilateral internal mammary lymph node (s) } \\
\text { and axillary lymph nodes (s). }\end{array}$ \\
\hline $\mathrm{N} 3 \mathrm{c}$ & Metastases in ipsilateral supraclavicular lymph node (s \\
\hline
\end{tabular}

Table 3: Regional Lymph Nodes (N), pathological evaluation

\begin{tabular}{|c|c|}
\hline \multicolumn{2}{|c|}{ Pathological } \\
\hline $\mathrm{pNX}$ & $\begin{array}{l}\text { Regional lymph nodes cannot be assessed (e.g., previously re- } \\
\text { moved or not removed for pathologic study) }\end{array}$ \\
\hline pN0 & No regional lymph node metastases identified histologically. \\
\hline \multirow{5}{*}{$\mathrm{pN} 1$} & Micrometastases \\
\hline & OR \\
\hline & Metastases in 1 to 3 axillary lymph nodes. \\
\hline & AND / OR \\
\hline & $\begin{array}{l}\text { Metastases in internal mammary nodes with metastases detected } \\
\text { by sentinel lymph node biopsy but not by clinically detected. }\end{array}$ \\
\hline $\begin{array}{l}\mathrm{pN} 1 \\
\mathrm{mi}\end{array}$ & Micrometastases $(>0.2 \mathrm{~mm}$ and $/ \mathrm{or}>200$ cells but none $>2.0 \mathrm{~mm})$ \\
\hline pN1a & $\begin{array}{l}\text { Metastases in 1-3 axillary lymph nodes, at least one metastases } \\
>2.0 \mathrm{~mm}\end{array}$ \\
\hline $\mathrm{pN} 1 \mathrm{~b}$ & $\begin{array}{l}\text { Metastases in internal mammary nodes with micrometastases or } \\
\text { macrometastases detected by sentinel lymph node biopsy but not } \\
\text { clinically detected. }\end{array}$ \\
\hline $\mathrm{pN} 1 \mathrm{c}$ & $\begin{array}{l}\text { Metastases in 1-3 axillary lymph nodes and in internal mammary } \\
\text { lymph nodes with micrometastases or macrometastases detected } \\
\text { by sentinel lymph node biopsy but not clinically detected. }\end{array}$ \\
\hline \multirow{3}{*}{$\mathrm{pN} 2$} & Metastases in 4-9 axillary lymph nodes. \\
\hline & OR \\
\hline & $\begin{array}{l}\text { Metastases in clinically detected internal mammary lymph nodes } \\
\text { in the absence of axillary lymph node metastases. }\end{array}$ \\
\hline $\mathrm{pN} 2 \mathrm{a}$ & $\begin{array}{l}\text { Metastases in 4-9 axillary lymph nodes (at least } 1 \text { tumor deposit } \\
>2 \mathrm{~mm} \text { ). }\end{array}$ \\
\hline $\mathrm{pN} 2 \mathrm{~b}$ & $\begin{array}{l}\text { Metastases in clinically detected internal mammary lymph nodes } \\
\text { in the absence of axillary lymph node metastases. }\end{array}$ \\
\hline \multirow{9}{*}{$\mathrm{pN} 3$} & Metastases in $\geq 10$ axillary lymph nodes. \\
\hline & OR \\
\hline & Metastases in infraclavicular (level III axillary) lymph nodes. \\
\hline & OR \\
\hline & $\begin{array}{l}\text { Metastases in clinically detected ipsilateral internal mammary } \\
\text { lymph nodes in the presence of one or more positive level I, II } \\
\text { axillary lymph nodes. }\end{array}$ \\
\hline & OR \\
\hline & $\begin{array}{l}\text { Metastases in }>3 \text { axillary lymph nodes and in internal mammary } \\
\text { lymph nodes with micrometastases or macrometastases detected } \\
\text { by sentinel lymph node biopsy but not clinically detected. }\end{array}$ \\
\hline & OR \\
\hline & Metastases in ipsilateral supraclavicular lymph nodes. \\
\hline \multirow{3}{*}{$\mathrm{pN} 3 \mathrm{a}$} & $\begin{array}{l}\text { Metastases in } \geq 10 \text { axillary lymph nodes (at least } 1 \text { tumor deposit } \\
>2.0 \mathrm{~mm} \text { ) }\end{array}$ \\
\hline & OR \\
\hline & Metastases to the infraclavicular (level III axillary lymph nodes). \\
\hline \multirow{3}{*}{$\mathrm{pN} 3 \mathrm{~b}$} & $\begin{array}{l}\text { Metastases in clinically detected ipsilateral internal mammary } \\
\text { lymph nodes in the presence of one or more positive axillary } \\
\text { lymph nodes. }\end{array}$ \\
\hline & OR \\
\hline & $\begin{array}{l}\text { Metastases in }>3 \text { axillary lymph nodes and in internal mammary } \\
\text { lymph nodes with micrometastases or macrometastases detected } \\
\text { by sentinel lymph node biopsy but not clinically detected. }\end{array}$ \\
\hline $\mathrm{pN} 3 \mathrm{c}$ & Metastases in ipsilateral supraclavicular lymph nodes. \\
\hline
\end{tabular}


Blood Born Metastasis: Bones are the most common site of blood bourn distant metastasis, followed by lung and pleura, liver, ovary, adrenal gland, and central nervous system. Invasive lobular carcinoma has a peculiar tendency to metastasize to the abdominal cavity, especially to the gastrointestinal tract, ovaries, and serosal surfaces. Meninges has a particular tendency to host the metastatic breast carcinoma ${ }^{[33]}$. Brain metastases are more likely with basal like tumours, that are ER-PR negative, CK5/6 positive and over-express HER2/neu or EGFR ${ }^{[34]}$. Various type of Immunohistochemical markers (particulary keratin group) are used to detect occult breast carcinoma especially bone marrow. These markers are mainly useful in cases of lobular carcinoma, which can be easily missed in H\&E stained sections. Recently, PCR (RT-PCR) assays for keratin 19, MUC1, and mammoglobin have been used to detect occult breast carcinomas in bone marrow, lymph nodes, or peripheral blood ${ }^{[35]}$. When the metastatic breast carcinoma is poorly differentiated and difficult to know the primary site of the tumour based on microscopic features only, GCDFP-15, mammaglobin, lactalbumin, and hormone receptors strongly suggests a breast primary, especially when combined $^{[36]}$ (Table 4).

Table 4: Distant Metastases (M)

\begin{tabular}{|l|l|}
\hline Symbol & Metastasis status \\
\hline M0 & No clinical or radiographic evidence of distant metastases. \\
\hline cM0 $(\mathrm{i}+)$ & $\begin{array}{l}\text { No clinical or radiographic evidence of distant metastases, } \\
\text { but deposits of molecularly or microscopically detected } \\
\text { tumor cells in circulating blood, bone marrow or other } \\
\text { non-regional nodal tissue that are no larger than } 0.2 \mathrm{~mm} \text { in } \\
\text { a patient without symptoms or signs of metastases }\end{array}$ \\
\hline M1 & $\begin{array}{l}\text { Distant detectable metastases as determined by classic } \\
\text { clinical and radiographic means and/or histologically } \\
\text { proven }>0.2 \mathrm{~mm} .\end{array}$ \\
\hline
\end{tabular}

\section{Staging}

The extent or stage of cancer at the time of diagnosis is a key factor that defines prognosis and is a critical element in determining appropriate treatment based on the experience and outcomes of groups of prior patients with similar stage. In addition, accurate staging is necessary to evaluate the results of treatments and clinical trials, to facilitate the exchange and comparison of information among treatment centers, and to serve as a basis for clinical and translational cancer research ${ }^{[37]}$. The most widely used clinical staging system for breast carcinoma is based on the TNM system (Tumour nodes metastases), it is adopted by both the International Union against Cancer (UICC) and the American Joint Commission on Cancer committee Staging and End Results Reporting (AJCC), details of latest breast tumour staging stated at the appendix (Table 5).
Table 5: Anatomic Stage

\begin{tabular}{|c|c|c|c|}
\hline Group & Clinical & & \\
\hline Stage & $\mathrm{T}$ & $\mathrm{N}$ & $\mathrm{M}$ \\
\hline 0 & Tis & No & M0 \\
\hline IA & $\mathrm{T} 1 \mathrm{~b}$ & No & M0 \\
\hline \multirow[t]{2}{*}{ IB } & T0 & N1mi & M0 \\
\hline & $\mathrm{T} 1 \mathrm{~b}$ & N1mi & M0 \\
\hline \multirow[t]{3}{*}{ IIA } & T0 & N1c & M0 \\
\hline & $\mathrm{T} 1 \mathrm{~b}$ & N1c & M0 \\
\hline & $\mathrm{T} 2$ & No & M0 \\
\hline \multirow[t]{2}{*}{ IIB } & $\mathrm{T} 2$ & N1 & M0 \\
\hline & $\mathrm{T} 3$ & No & M0 \\
\hline \multirow[t]{5}{*}{ IIIA } & T0 & $\mathrm{N} 2$ & M0 \\
\hline & $\mathrm{T} 1 \mathrm{~b}$ & $\mathrm{~N} 2$ & M0 \\
\hline & $\mathrm{T} 2$ & N2 & M0 \\
\hline & $\mathrm{T} 3$ & N1 & M0 \\
\hline & $\mathrm{T} 3$ & $\mathrm{~N} 2$ & M0 \\
\hline \multirow[t]{3}{*}{ IIIB } & $\mathrm{T} 4$ & No & M0 \\
\hline & $\mathrm{T} 4$ & N1 & M0 \\
\hline & $\mathrm{T} 4$ & $\mathrm{~N} 2$ & $\mathrm{MO}$ \\
\hline IIIC & Any $\mathrm{T}$ & N3 & M0 \\
\hline IV & Any $\mathrm{T}$ & Any N & M1 \\
\hline
\end{tabular}

Modified AJCC Cancer Staging (37)

\section{Prognostic factors of breast carcinoma}

There are so many clinical and pathological prognostic factors impact the outcome of the breast cancer, there are five cardinal independent prognostic factors including the tumour size, histological grade, histological subtype, lymph node status, and lymphovascular permeation, meanwhile, there are so many other significant prognostic factors are listed below

Tumour size: Tumour size is an important prognostic factor. Even among patients with as small as $1 \mathrm{~cm}$. It is the strongest independent parameter predicts the outcome of the disease. It has also been found that size determination has a greater prognostic significance when measured microscopically ${ }^{[6]}$.

Lymph node status: The status of the axillary lymph nodes is the most important single prognostic factor for patients with breast cancer. Numerous studies have shown that disease - free time and overall survival rates decrease as the number of positive nodes increases ${ }^{[3]}$. The prognosis also depends on the level of axillary node involved, the absolute number of lymph nodes involved, the amount of metastatic tumour, the presence, or absence of both extranodal spread and tumour cells in the efferent vessels $^{[6]}$.

Histological (cyto-architectural) type: Most of the special histological subtypes of breast cancer are associated with a particular clinical outcome, but there is no significant prognostic difference between classical invasive ductal and invasive lobular carcinoma. The special subtypes of IDC well known to have good prognosis are tubular carcinoma, cribriform carcinoma, medullary carcinoma, pure mucinous carcinoma, papillary car- 
cinoma, adenoid cystic carcinoma, and secretory (juvenile) carcinoma. While morphological subtypes with bad prognosis are inflammatory carcinoma, squamous cell carcinoma, metaplastic carcinoma, carcinomas with neuroendocrine features, and signet ring lobular carcinoma ${ }^{[6]}$.

Histological Grade: Tumour grade is an unique independent prognostic predictive factors for all invasive breast cancer, especially when it combined with histological type, in which they provides a more accurate assessment of prognosis than does histological grade alone ${ }^{[38]}$. Grading is recommended for all invasive carcinomas of the breast, regardless of morphological type. This practice is not accepted by some pathologists, who feel that grading is not appropriate for the special histological types with particular clinical behavior and outcome, such as pure tubular, invasive cribriform, mucinous, medullary and infiltrating lobular carcinomas. Poorly differentiated invasive carcinoma with high grade usually implies poor prognosis and high incidence of distant metastasis, independent of lymph node status and tumour size, no wonder; it has prognostic value even in breast cancers of $1 \mathrm{~cm}$ size and smaller ${ }^{[3]}$. The optimal grading method has been detailed earlier in this article.

Lymphovascular Permeation: It has been shown that detection of lymphatic vessels permeation is an important independent prognostic factor, especially when the tumour size is still of T1 and has no clinical lymph node involvement. It indicates adverse prognosis and increased risk of axillary lymph node involvement. Blood vessel invasion shows a high correlation with tumour size, histologic grade, tumour subtype, lymph node status, development of distant metastases and poor prognosis ${ }^{[3]}$ (Table 4).

Patient's Age: Young women under 35 years of age usually developed high-grade tumours, with bad prognosis, and having higher risk for recurrence and distance metastasis. While those women who are 35-50 years of age has better prognosis than those patient above 50 years old ${ }^{[6]}$.

DCIS And Invasiveness Status: It is noteworthy to say, DCIS lesion can be permanently eliminated by mastectomy. For mixed lesion, having both DCIS and invasive components, nodal metastasis is directly proportion with the amount of invasive component. Sometime extensive DCIS of comedo type can be associated with nodal metastasis without overt stromal invasion ${ }^{[6]}$. The presence of an extensive intraductal component is a prognostic factor for local recurrence in patients treated with conservative surgery and radiation therapy ${ }^{[3]}$.

Tumour Necrosis: Tumours with high grade, usually associated with necrosis which is some time extensive and accompanied with lymph node metastasis and bad prognosis ${ }^{[39]}$.

Inflammatory Cell Infiltrates: Some tumours associated with lymphocytic infiltrate which in particular tumour become as a diagnostic criteria as in medullary carcinoma, in general tumour with no inflammatory reaction associated with lesser incidence of lymph node metastasis and ultimately having better progno$\operatorname{sis}^{[40]}$.
Steroid Hormone Receptors: Immunohistochemical estimation of ER and PR in breast cancer sections has been a routine clinical practice since 20 years or more, approximately $60 \%$ of all breast carcinoma express ER/PR protein, which are associated with favorable outcome, but these tumours did shows significant metastatic potential. ER status very essential to predict tumour response to hormonal adjuvant therapy ${ }^{[3]}$.

The ERBB2 / HER2 Oncogene: Immunohistochemical estimation of Her2 oncogene, then validation of positive results by FISH or CISH, is a routine clinical practice in daily pathology workflow. Its expression is predicting the response to Herceptin therapy, but it is weak predictor of response to chemotherapy. Its usually associated with poor outcome especially in high grade tumours and in node positive tumours ${ }^{[6]}$.

Skin Invasion: Skin invasion in breast cancer is a bad prognostic sign, it would have ominous outcome especially when it associated with dermal lymph vessels invasion ${ }^{[6]}$.

E-Cadherin Status: E-cadherin is constantly express in all IDC, while the opposite is true in ILC, in which it play no role as prognostic parameter, but some studies shown that loss of E-cadherin in IDC associated with low survival rate ${ }^{[41]}$.

Vimentin Expression: Vimentin expression is a rather rare finding in invasive breast cancer. A hypothesis proposes that vimentin-expressing breast carcinomas may derive from breast progenitor cells with bilinear (glandular and myoepithelial) differentiation potential ${ }^{[42]}$. Makki J., et $\mathrm{al}^{[43]}$ found that vimentin was expressed in $32.93 \%$ (55/167) of breast carcinoma, they hypothesized that vimentin expression was either due to epithelial to mesenchymal transition (EMT) or the tumour cells derived from basal cell progenitors which can express both vimentin and E-cadherin. Vimentin expression in breast cancer is associated with poor prognosis; vimentin may be a convenient predictor of biological behavior for node-negative ductal NOS breast carcinomas $^{[44]}$.

Telomerase Activity: Recent studies detected a progressive increase in the prevalence of telomerase activity with the progression of breast cancer: $57.8 \%$ in DCIS lesions and 64\% in infiltrative component, with higher expression in metastatic lesions compared to primary lesion ${ }^{[43]}$, consequently Telomerase activity considered as a marker of disease progression, associated with stepwise breast tumour progression ${ }^{[45]}$. Estimation of Telomerase activity in breast cancer is not predictor of prognosis ${ }^{[46]}$. It is reflecting the proliferative index of the tumour.

Cancer Stem Cells (CSC): The expression of breast cancer stem cells harboring CD44+CD24-/low phenotype was associated with poor prognosis and predicts lymph node metastasis, Their absence indicate favorable outcome, while their expression is a bad prognostic sign ${ }^{[47]}$. Recent study suggest that breast CSC of CD44+CD24-/low phenotype should be included in future validation studies as a prognostic marker in breast cancer ${ }^{[43]}$. Estimating the frequency of breast CSC in different histological subtype of breast cancer can predict the clinical outcome and prognostic clues of each particular subtype of breast cancer ${ }^{[43]}$. 
Epithelial To Mesenchymal Transition (EMT): EMT is the loss of epithelial differentiation and gain the mesenchymal phenotype. A recent study has demonstrated a clear variation in the occurrence of EMT phenomena in different subtypes of breast cancers, as well as in various stages of the disease. It was more prevalent in DCIS lesion, triple negative breast tumours, and in metastatic lesions ${ }^{[43]}$. New data suggest that the increased proportion and prevalence of tumour cells with CD44+/CD24-/low and vimentin+/E-cadherin- phenotype, in DCIS and metastatic lesion may play an important role in tumour invasiveness and $\operatorname{aggressiveness}^{[47]}$.

Molecular Prognostic Factors: Recently some molecular factors have been identified as a parameter to predict prognosis and response to therapeutic modalities, like p53 mutation and $\mathrm{Bcl}-2$ amplification, which associated with high recurrence rate and low overall survival rate. Recent workgroup used proteomic and gene expression techniques to study multiple genes and try to link the gene-expression findings to clinical outcome. Among those new techniques, measurement of ER mRNA expression and Oncotype DX ${ }^{\mathrm{TM}}$ for the diagnosis of ER-positive breast cancers, and "Amsterdam Signature", to evaluate the patient need for chemotherapy or not ${ }^{[49]}$.

\section{Conclusion}

We are looking for further studies to improve current prognostic markers that will reflect on better treatment tools.

Conflict of Interest: I have no Conflict of interest

\section{References}

1. Lakhani, S.R., Ellis, I.O., Schnitt, S.J., et al. WHO Classification of Tumours of the Breast 4th edn. (2012).

2. Peter, B., Bernard, L. World cancer report. (2008) WHO, IARC press

3. Fattaneh, A.T., Peter, D. Pathology and Genetics of Tumours of the Breast and Female Genital Organs. (2003) IARC Press.

4. Vinay, K., Abul, K.A., Jon, C., et al. Robbins and Cotran Pathologic Basis of Disease 8th edn. (2010).

5. Eheman, C.R., Shaw, K.M., Ryerson, A.B., et al. The changing incidence of in situ and invasive ductal and lobular breast carcinomas. (2009) Cancer Epidemiol Biomarkers Prev 18(6): 1763-1769.

6. Rosai, J. Rosai and Ackerman's Surgical Pathology 10th edn. (2011).

7. American Cancer Society Report (2013).

8. Carol, D., Jiemin, M., Leah, B., et al. Breast Cancer Statistics 2013. (2014) CA 64(1): 52-62.

9. Pasche, B. Cancer Genetics (Cancer Treatment and Research) 2010: 19-20.

10. Gage, M., Wattendorf, D., Henry, L.R. Translational advances regarding hereditary breast cancer syndromes. (2012) J Surg Oncol 105(5): 444-451.

11. Armstrong, K., Eisen, A., Weber, B. Assessing the risk of breast cancer. (2000) N Engl J Med 342(8): 564-571.

12. Biral, V. Breast cancer and replacement hormone- therapy in the Million Women Study. (2003) Lancet 362(9382): 419-427.

13. Pherson, K.M., Steel, C.M., Dixon, J.M. ABC of Breast Diseases. Breast cancer-epidemiology, risk factors, and genetics. (2000) BMJ 321(7261): 624-628.

14. Newcomb, P.A., Storer, B.E., Longnecker, M.P., et al. Lactation and a reduced risk of premenopausal breast cancer. (1994) N Engl J Med 330(2): 81-87.

15. Gunter, M.J., Hoover, D.R., Yu, H., et al. Insulin, Insulin-Like
Growth Factor-I, and Risk of Breast Cancer in Postmenopausal Women. (2009) J Natl Cancer Inst 101(1): 48-60.

16. Ewertz, M., Holmberg, L., Tretli, S., et al. Risk factors for male breast cancer. (2001) Acta Oncol 40(4): 467-471.

17. Fackenthal, J.D., Marsh, D.J., Richardson, A.L., et al. Male breast cancer in Cowden syndrome patients with germline PTEN mutations. (2001) J Med Genet 38(3): 159-164.

18. Alcohol consumption and ethyl carbamate: A Working Group on the Evaluation of Carcinogenic Risks to Humans. (2007) IARC 96.

19. Protani, M., Coory, M., Martin, J.H. Effect of obesity on survival of women with breast cancer: systematic review and meta-analysis. (2010) Breast Cancer Res Treat 123(3): 627-635.

20. Press release from AICR annual meeting (2011).

21. Tan, D.S., Marchio, C., Reis-Filho, J.S. Hereditary breast cancer: from molecular pathology to tailored therapies. (2008) J Clin Pathol 61(10): 1073-1082.

22. Wooster, R., Weber, B.L. Breast and ovarian cancer. (2003) N Engl J Med 348(23): 2339-2347.

23. Clapp, R.W., Jacobs, M.M., Loechler, E.L. Environmental and occupational causes of cancer: new evidence 2005-2007. (2008) Rev Environ Health 23 (1): 1-37.

24. Clinical practice guidelines, management of breast cancer. (2010) Malaysian $\mathrm{MOH}$ and Academy of Medicine Malaysia.

25. Darbre, P.D. Recorded Quadrant Incidence of Female Breast Cancer in Great Britain Suggests a Disproportionate Increase in the Upper Outer Quadrant of the Breast. (2005) Anticancer Res 25(3c): 2543-2550 26. Scarff, R.W., Torloni, H. Histological typing of breast tumors. (1968) International histological classification of tumours (WHO) 2(2): 13-20.

27. Elston, C.W., Ellis, I.O. Pathological prognostic factors in breast cancer, the value of histological grade in breast cancer: experience from a large study with long-term follow-up. (1991) Histopathology 19(5): 403-410.

28. Damiani, S., Peterse, J.L., Eusebi, V. Malignant neoplasms infiltrating 'pseudoangiomatous' stromal hyperplasia of the breast: an unrecognised pathway of tumour spread. (2002) Histopathology 41(3): 208-215.

29. Goldstein, N.S. Does the level of E-cadherin expression correlate with the primary breast carcinoma infiltration pattern and type of systemic metastases? (2002) Am J Clin Pathol 118(3): 425-434.

30. Morimoto, T., Komaki, K., Inui, K., et al. Involvement of nipple and areola in early breast cancer. (1985) Cancer 55(10): 2459-2463.

31. Schmidt, W.A., Boudousquie, A.C., Vetto, J.T., et al. Lymph nodes in the human female breast: a review of their detection and significance. (2001) Hum Pathol 32(2): 178-187.

32. Veronesi, U., Cascinelli, N., Bufalino, R., et al. Risk of internal mammary lymph node metastases and its relevance on prognosis of breast cancer patients. (1983) Ann Surg 198(6): 681-684.

33. Miller, R.E. Breast cancer and meningioma. (1986) J Surg Oncol 31(3): 182-183.

34. Hicks, D.G., Short, S.M., Prescott, N.L., et al. Breast cancers with brain metastases are more likely to be estrogen receptor negative, express the basal cytokeratin CK5/6, and overexpress HER2 or EGFR. (2006) Am J Surg Pathol 30(9): 1097-1104.

35. Ozbas, S., Dafydd, H., Purushotham, A.D. Bone marrow micrometastasis in breast cancer. (2003) Br J Surg 90(3): 290-301.

36. Nonaka, D., Chiriboga, L., Soslow, R.A. Expression of pax8 as a useful marker in distinguishing ovarian carcinomas from mammary carcinomas. (2008) Am J Surg Pathol 32(10): 1566-1571.

37. Edge, S.B., Byrd, D.R. AJCC Cancer Staging Manual 7th edn. (2010).

38. Pereira, H., Pinder, S.E., Sibbering, D.M.,et al. Pathological prognostic factors in breast cancer. IV: Should you be a typer or a grader? A comparative study of two histological prognostic features in operable breast carcinoma. (1995) Histopathology 27(3): 219-222.

39. Yu, L., Yang, W., Cai, X., et al. Centrally necrotizing carcinoma of the breast: clinicopathological analysis of 33 cases indicating its bas- 
al-like phenotype and poor prognosis. (2010) Histopathology 57(2): 193-201.

40. Fisher, E.R., Kotwal, N., Hermann, C., et al. Types of tumor lymphoid response and sinus histiocytosis. (1983) Arch Pathol Lab Med 107(5): 222-227.

41. Rakha, E.A., Abd El Rehim, D., Pinder, S.E., et al. E-cadherin expression in invasive non-lobular carcinoma of the breast and its prognostic significance. (2005) Histopathology 46(6): 685-693.

42. Korsching, E., Packeisen, J., Liedtke, C., et al. The origin of vimentin expression in invasive breast cancer: epithelial-mesenchymal transition, myoepithelial histogenesis or histogenesis from progenitor cells with bilinear differentiation potential? (2005) J Pathol 206(4): 451-457. 43. Makki, J., Myint, O., Wynn, A.A., et al. Expression Distribution of Cancer Stem Cells, Epithelial to Mesenchymal Transition, and Telomerase Activity in Breast Cancer and Their Association with Clinicopathologic Characteristics. (2015) Clin Med Insights Pathol 8: 1-16.
44. Domagala, W., Lasota, J., Dukowicz, A., et al. Vimentin expression appears to be associated with poor prognosis in node-negative ductal NOS breast carcinomas. (1990) Am J Pathol 137(6): 1299-1304.

45. Makki, J. Telomerase activity in breast cancer, promising marker of disease progression. (2015) Telomere and Telomerase 2(1): e681.

46. Carey, L.A., Nam, W.K., Goodman, S., et al. Telomerase activity and prognosis in primary breast cancers. (1999) J Clin Oncol 17(10): 3075-3081.

47. Makki, J. Breast cancer stem cells and epithelial to mesenchymal transition, their putative role in tumor initiation, propagation, and metastasis. (2015) Cancer Cell \& Microenvironment 2(2): e842.

48. Kaplan, R.N., Riba, R.D., Zacharoulis, S., et al. VEGFR1-positive haematopoietic bone marrow progenitors initiate the pre-metastatic niche. (2005) Nature 438(7069): 820-827.

49. Giuseppe, T., Maria, E.F., Gaia, S. Molecular prognostic factors: clinical implications in patients with breast cancer. (2008) Cancer Therapy 6: $773-782$. 